\title{
Primary tuberculosis of the thyroid gland
}

\author{
Ines Zendah, Hafaoua Daghfous, Sonia Ben Mrad, Fatma Tritar
}

Abderrahmene Mami Hospital of Pneumology, C Pneumology Department, Tunis, Tunisia

\begin{abstract}
Thyroid tuberculosis is a rare disease even in countries in which tuberculosis (TB) constitutes an endemic disorder. The diagnosis is often difficult as the clinical presentation has no distinct characteristics. We report a 47-year-old woman who presented with a painful nodular swelling of the neck, confirmed by physical examination and sweating. Ultrasonography disclosed nodules of the pyramidal lobe with cystic change, and bilateral multiple hypoechogenic lymph nodes along the jugular and carotid chains. Thyroid function tests were in the normal range, there were no signs of inflammation and the tuberculin test was negative. There was no evidence of tuberculosis in any other organ. The patient had surgery in which the pyramidal lobe was removed. Microscopic examination of the thyroid parenchyma and the excised lymph node revealed necrotizing epithelioid granulomas with Langhans' giant cells. The diagnosis of thyroid tuberculosis was therefore made. The patient was put on isoniazid, rifampicin, ethambutol and pyrazinamid for the subsequent 2 months and was subsequently given isoniazid and rifampicin for the subsequent 6 months with a favourable outcome. Although seldom observed, tuberculosis should be kept in mind in the differential diagnosis of nodular lesions of the thyroid.
\end{abstract}

Keywords: Extra-pulmonary tuberculosis, Neck swelling, Thyroid Tuberculosis

\section{INTRODUCTION}

Thyroid tuberculosis is rare even in countries in which tuberculosis $(\mathrm{TB})$ constitutes an endemic disorder, barely 200 cases having been reported in the world literature. TB of the thyroid can present as a mid-line neck mass and hence differential diagnosis with other more frequent pathologic entities, such as thyroglossal duct cyst, lipomas or thyroid neoplasia (lymphoma, thyroid cancer), should be made.

\footnotetext{
Address for correspondence:

Ines Zendah, C Pneumology Department, Abderrahmene

Mami, Hospital of Pneumology, 2080 Tunis, Tunisia,

Tel: +216 98602362, Fax: +216 71821184,

e-mail: ines_zen@yahoo.fr

Received 22-04-08, Revised 10-08-08, Accepted 01-09-08
}

Specific diagnosis is important as drug treatment is effective.

\section{CASE REPORT}

A 47-year-old female, non smoker, with no significant past medical history, presented with a 5-month history of a nodular swelling of the neck. The patient also reported nocturnal mass without fever for the past year. There was no history of weight loss, anorexia or asthenia. Physical examination revealed a 2 $\mathrm{cm}$ nodular mid-line mass in the anterior neck which seemed to be separate from the thyroid gland. The throat was normal. Body temperature was $37^{\circ} \mathrm{C}$, the heart rate was $70 / \mathrm{min}$, and blood pressure was $130 / 80$ 
mm Hg. Enlarged lymph nodes were not palpable. Chest examination was normal. Thyroid function tests were in the normal range. The blood count was as follows: haematocrit: $32.7 \%$, haemoglobin: $10.7 \mathrm{~g} / \mathrm{dl}$, platelets: $424.000 / \mathrm{mm}^{3}$, WBC: $7000 / \mathrm{mm}^{3}$ with a normal differential count. Erythrocyte sedimentation rate was $5 \mathrm{~mm}$ in the first hour and the $\mathrm{C}$ reactive protein (CRP) was $2.95 \mathrm{mg} / \mathrm{l}$ (normal value $<5 \mathrm{mg} / \mathrm{l}$ ). The liver enzymes were normal. Ultrasonography of the neck revealed that the pyramidal lobe of the thyroid gland contained many nodules with cystic changes resulting in an enlargement of the gland. The rest of the gland had a normal echogenicity and regular margins. Bilateral multiple hypoechogenic nodules were detected along the jugular and carotid chains, the largest being $0.62 \mathrm{~cm}$ in diameter. The chest Xray was normal. Tuberculin test with purified protein derivative was negative. The patient had surgery which revealed a hypertrophy of the pyramidal lobe of the thyroid gland, the rest of the gland showing no abnormality. Resection of the pyramidal lobe was performed. On gross examination, the specimen was whitish and measured $3 \times 1 \mathrm{~cm}$. One small lymph node was attached to the specimen. Microscopic examination revealed necrotizing epithelioid granulomas with Langhans' giant cells. The lymph node included epitheloid cell granulomas and caseous necrosis. The diagnosis of thyroid and lymph node tuberculosis was therefore made. Acid fast bacilli (AFB) were absent in the sputum. Abdominal ultrasonography revealed no lymph node enlargement. The patient was placed on isoniazid (300 mg per day), rifampicin (600 mg per day), ethambutol (1200 mg per day) and pyrazinamid (1500 mg per day) for 2 months and isoniazid and rifampicin for the subsequent 6 months. The clinical outcome was good. Ultrasonography of the neck and of the abdomen at 8 months of antituberculous treatment revealed no abnormality of the thyroid gland. The enlarged lymph nodes of the jugular and carotid chains were not present.

\section{DISCUSSION}

Tuberculosis of the thyroid gland, whether primary or secondary, is an extremely rare disease with only isolated reports and a small number of case series having been reported in the literature, even in countries with endemic TB. ${ }^{1,2}$ The prevalence varies from
$0.1 \%$ to $0.6 \%$ in histologically diagnosed specimens, including areas with endemic TB. ${ }^{1,3-5}$ However, at least 200 cases have been recorded in the English language literature since the first case reported by Leber. ${ }^{6-11}$ The reason for the rarity of thyroid TB is unknown. ${ }^{12}$ In most cases, thyroid tuberculosis is secondary that is associated with another location of the disease. In such cases the thyroid is affected by bacillus spread via the haematogenous or lymphogenous route or directly from the larynx or cervical lymphadenitis. ${ }^{13,14}$ TB primarily affecting the thyroid gland is much more rare and, predictably, more difficult to diagnose.

Most frequently the patients are, as in our case, middle-aged women. ${ }^{14}$ Although dysphagia, dyspnea and more rarely dysphonia are the main symptoms of the disease, the patient may be asymptomatic. ${ }^{15}$ The most frequent clinical presentation is a solitary thyroid nodule that may present a cystic component. $13,14,16$ Our patient presented a swelling of the anterior neck which was thought to be outside the thyroid gland. Sometimes the patients present with thyrotoxicosis, hypothyroidism, thyroid abscess, thyroid enlargement mimicking cancer, or show signs of subacute granulomatous thyroiditis (De Quervain's) or of chronic non-suppurative thyroiditis. ${ }^{11,13,17,18}$ In the majority of cases, however, the patients are euthyroid and this was the case in our patient. ${ }^{9,14}$ Imaging techniques are not helpful in establishing the diagnosis. Ultrasonography mostly shows a heterogeneous, hypoechogenic mass that may include a cystic degeneration. ${ }^{9,19}$ Contrastenhanced CT may reveal a necrotic centre with a peripheral rim enhancement related to the caseous lesion along with regional lymphadenopathy. ${ }^{19} \mathrm{Tu}-$ berculous thyroiditis can mimic many pathologies. Localized pain is a predominant symptom and facilitates differential diagnosis in such cases. The other pathologies to consider are infectious thyroiditis and subacute granulomatous thyroiditis (De Quervain's, thyroid sarcoidosis, etc). ${ }^{20}$ In the event that pain is absent, tuberculous thyroiditis can often be mistaken for carcinoma. ${ }^{21-23}$ It is important to note that tuberculous thyroiditis may coexist with thyroid carcinoma in the same patient. ${ }^{24-26}$

The diagnosis is mainly made by ultrasound guided fine-needle aspiration cytology, a diagnostic step that helps to avoid unnecessary surgery. ${ }^{4,27,28}$ In most cases definite diagnosis is made post-operatively by means 
of histopathological examination of the surgical specimen, as in our patient. ${ }^{4,5,14}$ Since granulomatous lesions are not pathognomonic of tuberculosis, as they may be seen in sarcoidosis and subacute thyroiditis, the caseating necrosis, if present, confirms the diagnosis of tuberculosis. In our case, the tuberculous origin of the thyroid disease was confirmed by the presence of caseaum in the lymph node. The demonstration of AFB in the gland by Ziehl Nelsen stain can also validate the diagnosis. However, the mycobacteria are rarely recognised by the stain. ${ }^{15,29}$ Furthermore, the surgical specimen is rarely submitted for culture, as the tuberculosis is not suspected.

Treatment includes antituberculous drugs combined with surgical removal of the affected parts of the thyroid gland or surgical drainage, with a good outcome. ${ }^{4,5,27}$ For some authors drugs alone are sufficient. ${ }^{30}$ In our patient, although surgery was applied for the purpose of diagnosis, the affected lobe was also resected.

Besides surgical treatment, antituberculous drugs were given in accordance with our national antituberculosis program. The total duration of chemotherapy was 8 months with a favourable outcome.

In conclusion, Tuberculosis is an uncommon cause of thyroid disease. It can manifest in various ways with nonspecific symptoms. The diagnosis is difficult since thyroid tuberculosis needs to be differentiated from other diseases of the thyroid gland. The main method for establishing diagnosis is fine-needle aspiration with subsequent histological and bacteriological investigation, whereas in certain cases the dignosis is made only via histopathological examination of the resected gland. Treatment includes antituberculous drugs, surgery or repeated puncture drainage procedures, or combinations of these methods. A preoperative diagnosis of the disease can help in avoiding surgery in many patients.

\section{REFERENCES}

1. Collar FA, Huggins CB, 1926 Tuberculosis of the thyroid gland. Ann Surg 84: 804-820.

2. Kukreja HK, Sharma ML, 1982 Primary tuberculosis of the thyroid gland. Ind J Surg 44:190.

3. Rankin FW, Graham AS, 1932 Tuberculosis of the thyroid gland. Annals of Surgery 96: 625.
4. El Malki HO, Mohsine R, Benkhraba K, et al, 2006 Thyroid tuberculosis. Diagnosis and treatment. Chemotherapy 52: 46-49.

5. Kabiri H, Atoini F, Zidane A, 2007 Thyroid tuberculosis. Ann Endocrinol 68: 196-198.

6. Coller FA, Huggins CB, 1926 Tuberculosis of the thyroid gland. Ann Surg 84: 408.

7. Sadykov FG, Mukhtarov RS, 1987 Local form of tuberculosis of the thyroid gland in children. Vestn Khir Im I I Grek 139:114.

8. Pazaitou K, Chrisoulidou A, Ginikopoulou E, Angel J, Destouni C, Vainas I, 2002 Primary tuberculosis of the thyroid gland: report of three cases. Thyroid 12: 11371140.

9. Terzidis K, Tourli P, Kiapekou E, Alevizaki M, 2007 Thyroid Tuberculosis. Hormones (Athens) 6: 75-79.

10. Mondal A, Patra DK, 1995 Efficacy of fine needle aspiration cytology in the diagnosis of tuberculosis of the thyroid gland: a study of 18 cases. J Laryngol Otol 109: 36-38.

11. Ghosh A, Saha S, Bhattacharya B, Chattopadhay S, 2007 Primary tuberculosis of thyroid gland: a rare case report. Am J Otolaryngol. 28: 267-270.

12. Corton RS, Kumar V, Robbins SL 1994 In Robbins Pathological basis of disease, W.B. Saunders Company U.S, pp, 326, 382.

13. Das DK, Pant CS, Chachra KL, Gupta AK, 1992 Fine needle aspiration cytology diagnosis of tuberculous thyroiditis. A report of 8 cases. Acta Cytol 36: 517-522.

14. Abdulsalam F, Abdulaziz S, Mallik A, 2005 Primary Tuberculosis of the Thyroid Gland. KMJ 37: 116-118.

15. Khan EM, Haque I, Pandey R, Mishra SK, Sharma AK, 1993 Tuberculosis of the thyroid gland: a clinicopathological profile of four cases and review of the literature. Aust NZ J Surg. 63: 807-810.

16. Surer I, Ozturk H, Cetinkursun S, 2000 Unusual presentation of tuberculosis reactivation in childhood: an anterior neck mass. J Pediatr Surg 35: 1263-1265.

17. Barnes P, Weatherstone R, 1979 Tuberculosis of the thyroid. Two case reports. Br J Dis Chest 73:187-191.

18. Johnson AG, Phillips ME, Thomas RJS, 1973 Acute tuberculous abscess of the thyroid gland. Br J Surg 60: 608.

19. Kang BC, Lee SW, Shim SS, Choi HY, Baek SY, Cheon YJ, 2000 US and CT findings of tuberculosis of the thyroid gland: three case reports. Clin Imaging 24: 283-286.

20. Talwar VK, Gupta H, Kumar A, 2003 Isolated tuberculous thyroiditis JIACM 4: 238-239.

21. Magboo ML, Clark OH, 1990 Primary tuberculous thyroid abscess mimicking carcinoma diagnosed by fine needle aspiration biopsy West J Med 153: 657-659.

22. Alan R, O'Flynn W, Clarke SE, 1990 Tuberculosis of the thyroid bed presenting as recurrent medullary thyroid carcinoma. Tubercle 71: 301-302.

23. Al-Mulhim AA, Zakaria HM, Abdel Hadi MS, Al- 
Mulhim FA, Al-Tamimi DM, Wosornu L, 2002 Thyroid tuberculosis mimicking carcinoma: report of two cases. Surg Today 32: 1064-1067.

24. El Kohen A, Essakalli L, Amarti A, Benchekroun L, Jazouli N, Kzadri M, 2001 Thyroid tuberculosis associated with papillary microcarcinoma of the thyroid gland: a case report. Rev Laryngol Otol Rhinol 122: 205-208.

25. Hizawa K, Okamura K, Sato K, Kuroda T, Yoshinari M, Ikenoue H, 1990 Tuberculous thyroiditis and miliary tuberculosis manifested postpartum in a patient with thyroid carcinoma. Endocrinol Jpn 37: 571-576.

26. Hery A, Rakotoarisoa N, Riel AM, et al, 2007 La tuberculose de la glande thyroode: A propos de deux cas. Fr
ORL 92: 318-320.

27. Simkus A, 2004 Thyroid tuberculosis. Medicina (Kaunas) 40: 201-204.

28. Bulbuloglu E, Ciralik H, Okur E, Ozdemir G, Ezberci F, Cetinkaya A, 2006 Tuberculosis of the thyroid gland: review of the literature. World J Surg 30: 149-155.

29. Keven MC, Birengal S, Okca F, 2001 Tuberculosis of the thyroid gland: a case report. Clin Microbial Infect 7: 514.

30. El Malki HO, El Absi M, Mohsine R, Ait Taleb K, Chefchaouni MC, Oulbacha S, 2002 Tuberculosis of the thyroid. Diagnosis and treatment. Ann Chir 127: 385-387. 